\title{
EDUCAÇÃO AMBIENTAL NO TOCANTINS: A EXPERIÊNCIA DOS ESCOTEIROS DO BRASIL
}

\author{
Márcia Flausino Vieira Alves ${ }^{1}$ \\ Nádia Flausino Vieira Borges ${ }^{2}$ \\ Mariana da Silva Neta ${ }^{3}$ \\ Aldizia Carneiro de Araújo ${ }^{4}$ \\ Pablo Regis Andrade ${ }^{5}$ \\ Kátia Cristina Custódio Ferreira Brito ${ }^{6}$
}

\section{INTRODUÇÃO}

Em 1969 a imagem da Terra tocou comoveu o mundo quando a primeira foto do Planeta tirada do espaço foi publicada, a imagem do "Planeta Azul" desperta olhares, e debates, um incomparável ecossistema com incontáveis espécies. Para estimular à consciência coletiva e envolver todas as nações no projeto de proteção da natureza a Conferencia de Tbilisi é organizada UNESCO, em Estocolmo, em 1977, onde nascem as definições mundiais, princípios e estratégias para a AE no mundo.

A educação ambiental surge como instrumento apropriado para colaborar para a resolução de problemas na sociedade atual. Nessa perceptiva a educação dos indivíduos das sociedades precise ser organizada de forma sistemática para formar sujeitos ativos para atuarem como protagonistas em suas comunidades.

Nesse contexto nos questionamos: Qual a proposta do método educativo dos Escoteiros do Brasil e como a educação ambiental por eles desenvolvida pode contribuir para a formação dos jovens tocantinenses na perspectiva da formação para a ética e a cidadania?

\footnotetext{
${ }^{1}$ Pedagoga, Psicopedagoga, professora da educação básica da rede pública estadual do Tocantins e gerente do Sistema de Gerenciamento Escolar da Secretaria da Educação - SEDUC/TO. E-mail: marciaflausino@hotmail.com;

${ }^{2}$ Pedagoga, Mestre em Educação pela UFT, professora da educação básica da rede pública estadual do Tocantins Docente no Curso de Pós-Graduação em EJA na Diversidade e Inclusão Social da UFT. E-mail: nadiaflausino@uft.edu.br;

${ }^{3}$ Pedagoga e Licenciada em Letras; Especialista em Gestão Escolar; professora da educação básica da rede pública estadual do Tocantins e aluna do Programa de Pós-Graduação em Letras da Universidade Federal do Tocantins - UFT. E-mail: marianasneta@gmail.com;

${ }^{4}$ Pedagoga e licenciada em Letras; Especialista em Ensino de língua; professora da educação básica da rede pública estadual do Tocantins. E-mail: aldiziapedagoga@seduc.to.gov.br;

${ }^{5}$ Sociológo, Mestre em Sociologia, Professor na Faculdade Católica do Tocantins. E-mail: prandrade@bol.com.br;

${ }^{5}$ Pedagoga, Mestre em Engenharia de Produção pela UFSC, Doutoranda em Educação pela UFSCar, Professora do Colegiado de Pedagogia da UFT. E-mail: katiacristina@uft.edu.br;
} 
Conforme Silva e Imbernon (2014) o escotismo é o movimento de educação não-formal do mundo, e que utiliza de um método educativo próprio para promover o desenvolvimento das capacidades e interesses dos jovens, do despertar da consciência para a cidadania, a solidariedade e a sustentabilidade, através do sistema de progressão, aplicado de forma lúdica, da proposta do desafio e da superação das limitações. Para as autoras o movimento desenvolve uma linguagem comum e reconhece no conhecimento científico as estratégias necessárias para o desenvolvimento social e da cidadania.

O método educativo do movimento escoteiro ainda atinge todas as faixas etárias, e integra todas as pessoas a partir dos 6,5 anos. Propõe-se a alcançar pessoas de todas as idades, níveis sociais e nacionalidade, incentivando o interesse de todos na participação ativa resolução dos problemas socioambientais, econômicos e políticos da sua comunidade e do mundo.

Conforme JACOBI (2003, p.190):

A reflexão sobre as práticas sociais, em um contexto marcado pela degradação permanente do meio ambiente e do seu ecossistema, envolve uma necessária articulação com a produção de sentidos sobre a educação ambiental. A dimensão ambiental configura-se crescentemente como uma questão que envolve um conjunto de atores do universo educativo, potencializando o engajamento dos diversos sistemas de conhecimento, a capacitação de profissionais e a comunidade universitária numa perspectiva interdisciplinar. Nesse sentido, a produção de conhecimento deve necessariamente contemplar as inter-relações do meio natural com o social, incluindo a análise dos determinantes do processo, o papel dos diversos atores envolvidos e as formas de organização social que aumentam o poder das ações alternativas de um novo desenvolvimento, numa perspectiva que priorize novo perfil de desenvolvimento, com ênfase na sustentabilidade socioambiental.

Nessa perspectiva todo projeto educativo que prime pela prática do ensino da sustentabilidade garante a melhoria na qualidade de vida para todos, e a proposta educativa do Movimento Escoteiro vem ao encontro com essa necessidade, criado em 1907, e desenvolvido nas comunidades por voluntários da sociedade civil organizada,

o Escotismo é um movimento educacional de jovens, sem vínculo a partidos políticos, voluntário, que conta com a colaboração de adultos, e valoriza a participação de pessoas de todas as origens sociais, raças e credos, de acordo com seu Propósito, seus Princípios e o Método Escoteiro concebidos pelo Fundador Baden-Powell e adotados pela União dos Escoteiros do Brasil. O Propósito do Movimento Escoteiro é contribuir para que os jovens assumam seu próprio desenvolvimento, especialmente 
do caráter, ajudando-os a realizar suas plenas potencialidades físicas, intelectuais, sociais, afetivas e espirituais, como cidadãos responsáveis, participantes e úteis em suas comunidades, conforme definido pelo seu Projeto Educativo. (UEB, 2013, p.12)

Com essa pesquisa objetivamos conhecer o método educativo dos Escoteiros do Brasil para compreender as possibilidades da educação ambiental desenvolvida para a formação dos jovens tocantinenses na perspectiva da formação para a ética e a cidadania.

\section{MATERIAL E MÉTODOS}

Para o presente momento trazemos as contribuições da pesquisa bibliográfica e documental, um processo teórico que objetiva conhecer e embasar o caminhar do estudo. Nas palavras de Gil (2002) a pesquisa bibliográfica possibilita alcançar maior amplitude de informações, pois além de permitir reunir dados dispersos em inúmeras publicações ao longo do tempo auxilia, também, na construção de novos parâmetros teóricos. Para Lima e Mioto (2007, p. 38), "avançar na pesquisa bibliográfica implica em um conjunto ordenado de procedimentos que buscam por respostas de forma atenta ao objeto de estudo e que, por isso, não tem caráter aleatório".

A pesquisa documental é para Gil (2002) uma "fonte rica e estável de dados", não gera grandes custos, não implica em períodos longos de tempo, pois ao não exigir coleta de campo com contato direto com diferentes sujeitos otimizando o tempo, possibilita ainda um estudo minucioso de diversas fontes. Assemelha-se a pesquisa bibliográfica e o que as diferencia são as fontes.

As pesquisas bibliográficas e documentais se inter-relacionam nesse momento, possibilitando o avançar por meio de documentos contemporâneos ou antigos, permitindo o dialogo e o questionamento dos autores que em confronto com nosso olhar desvelando pistas para nossa questão.

Para Domingues (2006) a abordagem qualitativa diferencia-se das outras pesquisas pelo olhar e a atitude do pesquisador que busca desenvolver compreensões e não explicações, ou seja, não pretende responder a questões do tipo: "por quê?", já que esse modo de colocar a pergunta implica buscar relações de causalidade. 
Para realização da pesquisa documental, além dos documentos oficiais de política de educação no Brasil, foram levantados dados junto à União dos Escoteiros do Brasil (UEB) referente ao método educativo, projeto político pedagógico da instituição e sobre as metodologias empregadas para o desenvolvimento da educação escoteira, com ênfase também na educação ambiental.

\section{RESULTADOS E DISCUSSÃO}

Criado em 1907, pelo general inglês e Lorde Robert Stephenson Smyth Baden Powel, tornou-se um movimento mundial de educação social, baseada no voluntariado e numa organização sem fins lucrativos. Uma história mundialmente conhecida e contata em mais de 200 países. Na llha de Brownsea, no Canal da Mancha, Inglaterra, Baden-Powell realizou o primeiro acampamento escoteiro com vinte jovens que tinham entre 12 a 16 anos.

O acampamento teve excelentes resultados o que incentivou BadenPowell escreveu o livro Escotismo para Rapazes que foi publicado em 1908, publicado em seis fascículos, de janeiro a maio, vendido em bancas de jornais, e editado como livro com algumas alterações. As ideias de BP foram tão bem aceitas que em poucas semanas, centenas de grupos de jovens estavam formadas, praticando Escotismo.

O movimento se espalhou pelo mundo rapidamente, chegando à América do Sul em 1908, primeiramente no Chile. Em 1909 mais de 10.000 jovens realizaram uma exibição de suas perícias escoteiras no Palácio de Cristal, em Londres. E em 1910, desliga-se do Exército e dedicada ao crescimento e fortalecimento do Escotismo. (PAOLILLO \& IMBERNON, 2009).

Foi em 1916, sensibilizado pelo pedido das crianças menores que queriam participar do Movimento Escoteiro, Baden-Powell cria o Ramo Lobinho, baseado no Livro do Jângal, de Rudyard Kipling, com auxílio de sua irmã. Agnes, que assume a liderança dos trabalhos com os pequenos. Em 1917, é a vez das mulheres, sensibilizado pelo desejo das meninas de participar, é constituído o primeiro Conselho Internacional da Associação de Guias da Inglaterra. Em 1930, Lady Olave Baden-Powell, esposa de BP, é aclamada Chefe Guia Mundial, função que exerceu até a sua morte. O Escotismo recebe de William F. de Bois McLaren 
uma área de terra, na floresta de Epping, arredores de Londres, onde se instala Gilweel Parko centro de formação de chefes. A última presença pública de BadenPowell para os escoteiros foi em 1937.

A principal organização representativa internacional é a Organização Mundial do Movimento Escoteiro (OMME), WOSM em inglês, declarou em 2010 a existência de mais de 28 milhões afiliados ao movimento presentes em mais de 220 países, e mais de 500 milhões de jovens atendidos desde a sua criação na Inglaterra até os dias de hoje segundo as estatísticas integradas da WOSM, o que classifica o Movimento Escoteiro como o maior movimento de educação não formal do mundo. E para a compreensão desta classificação, passaremos a diante para as percepções dos pesquisadores sobre a educação formal e não formal.

Embora tenha sofrido algumas alterações, a prática do movimento escoteiro ainda segue os mesmos métodos e princípios propostos por seu fundador na maior parte do mundo. Em sua estrutura organizacional os jovens são separados em grupos por faixa etária para possibilitar o desenvolvimento de atividades adaptadas a sua idade e desenvolvimento. São distribuídos entre: Ramo Lobo, Ramo Escoteiro, Ramo Sênior e Ramo Pioneiro, conforme UEB (2013):

a) Alcateia - jovens de 7 a 10 anos 10 anos, chamados de Lobinhos e Lobinhas. Usa como marco simbólico o livro da Jângal, de Rudyard Kipling. As atividades incentivam a socialização pela diversão e execução de tarefas em equipes. Como oportunidade de desenvolvimento, o Ramo Lobo oferece jogos, trabalhos manuais, interpretação, canções, etc. além de instrução de técnicas Escoteiras.

b) Tropa Escoteira - jovens de 11 a 14 anos, chamados de escoteiros e escoteiras, baseado no estudo da natureza, vida mateira, exploração, campismo, fundamentado na vida em equipe e na participação comunitária. A principal característica está na oportunidade de viver uma aventura.

c) Tropa Sênior - jovens de 15 a 17 anos, chamados de sêniors e guias, desenvolvem suas atividades em torno dos desafios: físico, mental, espiritual, emocional, social, e de desenvolvimento do caráter, atendendo às características da idade de autoafirmação, e acentuando as ênfases nas atividades de desenvolvimento das reflexões e opiniões, aceitação e interesse pelo sexo oposto com ênfase no relacionamento respeitoso. 
d) Clã Pioneiro - jovens de 18 a 21 anos, chamados de pioneiros e pioneiras, é uma fraternidade de serviço ao próximo, que funciona como um centro de interesses, de realização de um projeto pessoal, de mútua ajuda e de serviço comunitário, promovendo as atividades de excursionismo e campismo sempre de maneira ecológica, cultural e social, e estimula os jovens a desenvolver a sua espiritualidade com vistas na perfeição de sua humanidade, e a desenvolver suas maturidade como cidadão feliz e participativo.

Independente do Ramo, o jovem escoteiro, assim chamados genericamente todos os que participam do movimento em todo o mundo, são beneficiados com as atividades escoteiras programadas e executadas pelo adulto voluntário, o Escotista. Todas as atividades são desenvolvidas em conformidade com a orientação dos princípios e do método escoteiro, sempre guiados pelos valores presentes nas ideias de $B-P$, sendo os princípios:

a) Dever para com Deus - crença e vivencia da fé em Deus, respeitando a expressão de fé dos demais;

b) Dever para com os outros - lealdade ao seu pais, em harmonia com a promoção da paz, compreensão e cooperação local, nacional e internacional, exercitadas na fraternidade escoteira. Participação no desenvolvimento da sociedade com reconhecimento e respeito à dignidade da pessoa humana e ao equilíbro do meio ambiente, fazendo sempre uma boa ação;

c) Dever para consigo mesmo - compromisso com seu desenvolvimento pessoal e crescimento saudável. (UEB, 2013, p. 12).

No sistema de progressão pessoal cada jovem é estimulado para que consiga desenvolver as suas capacidades e instigar seus interesses, a superar seus desafios, a ser um jovem explorador, a desenvolver o desejo pela aventura, ampliar o interesse por descobertas, a trabalhar criatividade. E para tanto o adulto organiza e realiza as atividades educativas baseadas no método escoteiro:

a) Aceitação da Promessa e da Lei Escoteira - todos os membros assumem, voluntariamente, um compromisso de vivência da Promessa e da Lei Escoteira.

b) Aprender fazendo - educando pela ação, o Escotismo valoriza:

- O aprendizado pela prática;

- O desenvolvimento da autonomia, baseado na autoconfiança e iniciativa;

- Os hábitos de observação, indução e dedução.

c) Vida em equipe - denominada nas Tropas de "Sistema de Patrulhas", incluindo:

- A descoberta e a aceitação progressiva de responsabilidade;

- A disciplina assumida voluntariamente;

- A capacidade tanto para cooperar como para liderar. 
d) Atividades progressivas, atraentes e variadas compreendendo: Jogos,

- Habilidades e técnicas úteis, estimuladas por um sistema de distintivos;

- Vida ao ar livre e em contato com a natureza;

- Interação com a comunidade;

- Mística e ambiente fraterno.

e) Desenvolvimento pessoal com orientação individual, considerando:

- A realidade e o ponto de vista de cada criança, adolescente ou jovem;

- A confiança nas potencialidades dos educandos;

- O exemplo pessoal do adulto;

- Seções com número limitado de jovens e faixa etária própria. (UEB, 2013, p. 14).

E desta forma, seguindo o princípio e o método desenvolvido pelo fundador do método educativo, Baden Powell, de forma cumulativa, a atividade comum se torna em atividade educativa escoteira onde o jovem é convidado a usar progressivamente a sua liberdade, assumindo a responsabilidade para com 0 cuidado consigo e com seu meio ambiente e social.

Conforme a Constituição da República Federativa do Brasil determina no artigo 255 que:

Todos têm direito ao meio ambiente ecologicamente equilibrado, bem de uso comum do povo e essencial à sadia qualidade de vida, impondo-se ao poder público e à coletividade o dever de defendê-lo e preservá-lo para as presentes e futuras gerações. (BRASIL, 1988).

A lei determina pela defesa e preservação do meio ambiente ecologicamente equilibrado, o determina como um bem de todos, dado pela coletividade e pelo Poder Público. E a única forma de garantir que as futuras gerações possam usufruir dos recursos naturais é protegendo o meio ambiente.

Com a missão de contribuir para a completa formação dos jovens, o método educativo do movimento escoteiro fundamenta o processo educativo no dever do homem para com Deus através da crença e vivencia de sua fé, no dever para com os outros na participação social e no serviço da cidadania, e no dever para consigo mesmo comprometido com seu desenvolvimento pessoal (UEB, 2013).

Segundo Guido et. al. (2013) é necessário suscitar discussões referentes à educação ambiental para que haja a possibilidade de intercâmbio entre o conhecimento construído e as práticas ambientais dentro e fora da escola. Cabe à educação ambiental um papel fundamental de educar os jovens e adultos para 0 desenvolvimento sustentável.

Baseado em um sistema de valores fundamentados na lei e na promessa escoteira, a educação ambiental do Movimento Escoteiro reconecta o homem a 
Deus e a natureza, valorizando a participação individual e a construção coletiva. Desenvolvido por adultos voluntários, desde a sua criação, no programa educativo o jovem é desafiado a assumir seu próprio desenvolvimento através do cultivo de valores como mundialmente referenciados como a pratica da sustentabilidade.

Para Luca, Andrade e Sorrentino (2012, p. 590) a educação ambiental ensina o jovem a relacionar com os outros seres humanos e com as demais formas de vida que nosso Planeta sustenta, para o autor, é "valorizando as relações e a forma como percebemos o Outro que a educação ambiental traz uma perspectiva de qualidade, de cuidado, de responsabilidade partilhada".

A ênfase primeira da educação do movimento escoteiro está na formação do cidadão, e nos estudos de Nascimento (2004, p. 70) vê-se que a grande difusão do movimento escoteiro "foi uma resposta social a um momento em que, através da educação, tentava-se reverter os males da degeneração física e moral causada pelas condições sociais da vida moderna".

Conforme descreve Martins (1929 apud Herold Junior 2011, p.4):

\section{O escotismo:}

Na sede - Moralidade, Civismo, Intelectualidade.

No Campo - Jogos Educativos, Vida no Campo, Educação Física, Ordem.

Se aplicado: Progresso e fraternidade.

Escoteiros:

Para a família: Bom filho, Bom pai, Bom irmão;

Para a pátria: Patriota, Educador, Trabalhador.

Depois dessa relação entre escotismo e educação estabelecida por Martins, compreendemos a educação escoteira como necessária para a formação das sociedades atuais, amplamente corrompidas pela competitividade e alcançada pela desumanização. Um povo que não se preocupa com o cuidado para com o seu próximo, não se preocupará com o cuidado com o meio ambiente e com a adoção de práticas sustentáveis.

Para Herold Júnior (2011) se todos os homens recebessem esses ensinamentos escoteiros, evitar-se-iam as guerras que se espalham por todo mundo, a miséria e a fome. Para o autor, um verdadeiro escoteiro jamais se curvará aos pés de um tirano para congratular, se não concordar com suas ideias.

\section{CONCLUSÕES}


Nos resultados da pesquisa bibliográfica e documental pudemos evidenciar a relevância do método educativo desenvolvida pelo Movimento Escoteiro na formação do cidadão seguindo seu princípio, e seu método educativo próprio e uma metodologia baseada no lúdico e na apresentação do desafio e da superação pessoal.

No trabalho em equipe e na vida ao ar livre, o método educativo incentiva os jovens a se desenvolver participando ativamente, e em integração com o meio ambiente natural e com a sua comunidade, primar pela melhoria na dinâmica das relações.

No programa de educação ambiental, o jovem é desafiado a assumir seu próprio desenvolvimento através do cultivo de valores como: disciplina, honra, responsabilidade e sustentabilidade, em escalas local, regional e global, contribuindo para a formação ética de cidadãos conscientes que atuam efetivamente para a construção de uma sociedade sustentável.

No escotismo o jovem não só aprende a respeitar a natureza, mas a conviver nela de forma responsável. Embora desenvolvido por diversos atores e em épocas distintas, podemos observar no método educativo a potencialidade de possibilitar o mesmo nível de desenvolvimento aos jovens de distintas sociedades e nações.

Foi evidenciado por essa pesquisa, que a educação ambiental desenvolvida através do programa de educação não-formal do Movimento Escoteiro constitui-se em um grande instrumento de formação de uma sociedade consciente de seus deveres para gestão sustentável do meio ambiente e para a preservação do Planeta, e consequentemente para a melhoria da qualidade de vida para todos.

Evidenciamos nos documentos analisados o incentivo para que o jovem assuma o papel de líder em sua comunidade, o que despertou o interesse dos pesquisadores que ao pesquisar a história de grandes líderes mundiais e grandes personalidades formadoras de opinião do último século, foi possível perceber que muitas dessas grandes personalidades como Juscelino Jubistschek, Itamar Franco, José Alencar, Jacques Chirac, Carol Wojtila (Papa João Paulo II), John Kennedy, Bill Clinton, Bill Gates, Barack Obama, dentre muitos outros.

\section{REFERÊNCIAS}


BRASIL, Senado Federal. Art. 225. 1988. Disponível em:

<http://www.senado.gov.br/atividade/const/con1988/con1988_07.

05.2015/art_225_.asp> Acesso Fev. 2016.

DOMINGUES, Maria Hermínia M. da S. A trajetória da pesquisa qualitativa. Brasília: Líber Livro Editora, 2006.

GIL, A. C. Como elaborar projetos de pesquisa. 4. ed. São Paulo: Atlas, 2002.

GUIDO, Lucia de Fátima Estevinho et al . Educação ambiental e cultura: articulando mídia e conhecimento popular sobre plantas. Trab. educ. saúde, Rio de Janeiro , v. 11, n. 1, p. 129-144, abr. 2013 . Disponível em <http://www.scielo.br/scielo.php?script=sci_arttext\&pid=S1981$77462013000100008 \&$ Ing=pt\&nrm=iso>. Acesso em Abr. 2016.

HEROLD JUNIOR, Carlos. A Educação Corporal no Paraná através do Movimento Escoteiro em Guarapuava (1927-1936). Educação em Revista | Belo Horizonte | v.27 | n.02 | p.123-150 ago. 2011. Disponível em: <http://www.scielo.br/pdf/edur/v27n2/a07v27n2> Acesso em: 18 Out 2014.

JACOBI, Pedro. EDUCAÇÃO AMBIENTAL, CIDADANIA E SUSTENTABILIDADE. Cadernos de Pesquisa, n. 118, março/ 2003 Cadernos de Pesquisa, n. 118, p. 189205, março/ 2003. Disponível em: <http://www.scielo.br/pdf/cp/n118/16834.pdf $\geq$ Acesso Maio 2016.

LIMA, Telma Cristiane Sasso de; MIOTO, Regina Célia Tamaso. Procedimentos metodológicos na construção do conhecimento científico: a pesquisa bibliográfica. 2007. Disponível em: <

http://www.scielo.br/scielo.php?script=sci_arttext\&pid=S1414-49802007000300004> Acesso Maio 2016.

LUCA, Andréa Quirino de; ANDRADE, Daniel Fonseca de; SORRENTINO, Marcos. O diálogo como objeto de pesquisa na educação ambiental. Educ. Real., Porto Alegre , v. 37, n. 2, p. 589-606, ago. 2012 . Disponível em <http://www.scielo.br/scielo.php?script=sci_arttext\&pid=S2175$62362012000200014 \&$ Ing=pt\&nrm=iso >. Acesso em Abr. 2016.

NASCIMENTO, Adalson de Oliveira. Educação e civismo: movimento escoteiro em Minas Gerais (1926-1930). Revista Brasileira de História da Educação, n. 7, p. 43-74, $2004 . \quad$ Disponível em: <http://www.rbhe.sbhe.org.br/index.php/rbhe/article/view/207/215> Acesso em: Out. 2015.

NASCIMENTO, Jorge Carvalho do. A escola de Baden-Powell: Cultura Escoteira, Associação Voluntária e Escotismo de Estado no Brasil. Rio de Janeiro: Imago, 2008.

PAOLILLO, C.; IMBERNON, R. A. L. Educação Ambiental e educação científica no contexto do Movimento Escoteiro. Escola de Artes, Ciências e Humanidades, USP. Revista Experiências em Ensino de Ciências. V4(2). São Paulo, Agosto. 2009. 
P.93-105.

Disponível

em

<http://www.if.ufrgs.br/eenci/artigos/Artigo_ID84/v4_n2_a2009> Acesso Fev. 2016.

SILVA, Camila Moreno de Lima; IMBERNON, Rosely Aparecida Liguori. Aspectos do Projeto Político Pedagógico do Movimento Escoteiro no Brasil e reflexos na Educação Ambiental. TERRAE DIDATICA 10-3:425-435 2014. Disponível em <https://www.ige.unicamp.br/terraedidatica/V10_3/PDF/TDv10-3-97.pdf >Acesso Maio 2016.

UEB, União dos Escoteiros do Brasil. Princípios, Organização e Regras (P.O.R). 10 Ed. Curitiba. 2013. 